\title{
Studies on Morphological, Cultural and Pathogenic Variability in Isolates of Fusarium oxysporum f.sp. pisi causing Wilt of Pea from Different Districts of Manipur, India
}

\author{
N. Kripalini ${ }^{*}{ }^{*}$, Mohan Kumar Biswas ${ }^{1}$ and Ph. Sobita Devi ${ }^{2}$ \\ ${ }^{1}$ Department of Plant Protection, Palli-Siksha Bhavana, \\ Sriniketan West Bengal-731236, India \\ ${ }^{2}$ Department of Plant Pathology, College of Agriculture, \\ CAU, Iroisemba, Imphal-795005, India \\ *Corresponding author
}

\section{A B S T R A C T}

\section{Keywords}

Pea, Fusarium oxysporum f.sp.pisi, Cultural,

Morphological, Pathological and variability

Article Info

Accepted:

18 October 2018

Available Online:

10 November 2018
Pea is one of the most important rabi pulse crops of India. Pea is being rich in protein are valuable for vegetable purpose. Fourteen isolates of Fusarium oxysporum f.sp.pisi from different districts of Manipur were studied for its cultural, morphological and pathogenic variability. The mycelia colour varied from white to light pink, purple and pale yellow colour. The radial growth of the isolates ranged from $5.4 \mathrm{~cm}$ to $8.9 \mathrm{~cm}$ at 8 days after inoculation at $26 \pm 10{ }^{\circ} \mathrm{C}$ in $90 \mathrm{~mm}$ petriplates. Sporulation of all isolates showed moderate to profuse. The size of micro conidia ranged from $11.6 \times 3.1$ to $25.2 \times 6.2 \mu \mathrm{m}$ and size of micro conidia ranged from $3.02 \times 2.1 \mu \mathrm{m}$ to $9.2 \times 5.6 \mu \mathrm{m}$. The number of septation of macroconidia was mostly 2-3 whereas in microconidia most of the isolates was found with no septum. The shape of the macroconidia is mostly sickle shaped. In microconidia most of the isolates are oval shaped. The conidial colours of all the isolates were found hyaline. The formation of chlamydospores ranged from ten to twentyone numbers of all the isolates on Potato Dextrose Agar medium. The dry weight mycelium showed variability in the weight of isolates which was ranged from 0.78 to $1.31 \mathrm{gm}$. In pathogenic variability, all the isolates exhibited wilt symptom and hence proved pathogenic on pea cultivars under artificial inoculation.

\section{Introduction}

Pea (Pisum sativum L.) is native of South Europe and gown a garden or field crop throughout the temperate regions of the world and was originally cultivated in the Mediterranean basin (Smartt, 1990; Sardana et al., 2007). In India, pea is one of the most important rabi pulse crops, in which the crop is grown on a field scale for its dry seeds and smaller scale for green peas. Peas being very rich in protein are valuable for vegetable purpose. It is rich source of protein, amino acid, sugar, carbohydrates, vitamins A and C, calcium and phosphorus besides having a small quantity of iron.

In Manipur field pea is one of the most important pulse crops grown in 26,000 ha. Area occupying about $85 \%$ of the total pulses 
area (Anonymous, 2015). However, the productivity of pulses in Manipur is very low due to several factors that are known to affect pea cultivation such as lack of improved varieties, tolerance to soil acidity, the most important being the diseases. Due to high humidity of region several disease caused by fungi, bacteria and viruses. Among these diseases, wilt caused by Fusarium oxysporum f.sp.pisi is the most destructive disease of the crop and occurs as an epiphyte almost every year. Fusarium is a soil-inhabiting fungus, surviving from year to year in the soil as thick-walled, very hardy spores that can sit in the soil surviving all kinds of conditions for more than 10 years. When the plant is in its early growth stage, the fungus kills it out right, but attack at the later stage, results in shriveled grains and heavy yield losses (Linford, 1928). During recent years, wilt of pea has become very serious in many pea growing areas of Manipur, so far not much research has been done. Therefore, the present study was undertaken with the objective to study the cultural, morphological and pathogenic variability of fourteen isolates of wilt pathogen (Fusarium oxysporum f.sp.pisi) present in different districts of Manipur.

\section{Materials and Methods}

\section{Collection of the samples and isolation of causal pathogen}

Diseased plants were collected from the field of different districts of Manipur i.e. Imphal West, Imphal East, Bishnupur, Thoubal, Tamenglong and Ukhrul districts during the year 2014-2015. The diseased samples were cut into small pieces of $2-3 \mathrm{~mm}$ size. These pieces were surface sterilized with $1 \%$ sodium hypochlorite solution for 2-3 minutes and then rinsed with distilled water. The sterilized pieces were then inoculated on PDA slants. The inoculated slants were incubated at $28 \pm$ $1^{0} \mathrm{C}$ for 7 days. After 7 days the fungal isolates appearing on the stem / root pieces were identified and transferred to PDA for purification. Identification of the causal fungus and pathogenicity test were carried out in the Department of Plant Pathology, College of Agriculture, CAU, Imphal. Culture was maintained on freshly prepared PDA slants inside the refrigerator and periodically sub cultured to fresh medium during the investigation.

\section{Cultural and morphological variability}

Fourteen isolates of F.o.f. sp. pisi were isolated from different districts of Manipur during the year 2014-2015. In order to study the cultural and morphological variability, $5 \mathrm{~mm}$ diameter of mycelia of each isolates were taken from the actively growing culture and placed centrally on $90 \mathrm{~mm}$ petridish containing solidified PDA medium and the inoculated plates were incubated at $26 \pm 1{ }^{0} \mathrm{C}$ for 7 days. Each plate is replicated three times. After seven days the growth pattern were observed daily and all the distinguishing characters such as pigmentation and sporulation were recorded. In morphological variability studies, average micro conidial, macroconidial size and chlamydospores number were recorded by observing under Binocular Microscope at 40x with the help of biowizard image analysis and measurement was done at $100 x$. For dry mycelium weight F.oxysporum f.sp.pisi isolates were grown on potato dextrose broth. Each $250 \mathrm{ml}$ flask having $200 \mathrm{ml}$ potato dextrose broth was inoculated with pure mycelia culture of F.oxysporum and incubated at $27 \pm 1^{\circ} \mathrm{C}$. After 15 days by filtration through Watman no. 1 filter paper mycelia mats were collected and washed with sterile distilled water. The harvest mycelia filtrate was dried at room temperature for 20 days. After drying it was weighed with electric balance. The experiment was replicates three times. 


\section{Pathogenic variability}

The pathogenic variability of fourteen isolates of Fusarium oxysporum f. sp. pisi were determined on the basis of pathogenicity test. In pathogenecity test, 14 isolates were mass multiplied on rice seed inoculum technique of (Weideman and Wehner, 1993) and inoculated $30 \mathrm{gm}$ per pot and cover with transparent polythene sheet and incubated for seven days on natural condition. After incubation, pea cultivars are sown in pots and three replications were maintained. Pots without inoculums served as control. Disease was recorded after emergence of seedlings. Wilt symptom observed on plants were graded into different category. Ranked is as minus (-) for no symptom and plus (+) for wilt symptom on inoculated pot. The appearance of disease symptom was categorized again into four groups viz., up to $25 \%$ wilt ranked as single plus (+), 25.1 to $50 \%$ ranked as double plus $(++), 50.1$ to $75 \%$ were ranked triple plus $(+++)$ and more than $75 \%$ were ranked tetra plus sign (++++) and reacted as slow pathogenic, moderate pathogenic, pathogenic and highly pathogenic isolates respectively.

\section{Results and Discussion}

\section{Identification of the causal pathogen}

Diseased samples were collected from the different pea growing districts of Manipur during the survey and isolation of the causal pathogen was carried out in the laboratory on potato dextrose agar (PDA). With repeated isolations, Fusarium oxysporum was consistently found to be associated with infected plants of pea. Fusarium oxysporum isolated from wilted pea plant were identified microscopically by their morphologically characteristics such as abundance of micro and fewer macro conidia and white to creamy white colour culture on PDA medium. Microconidia were cylindrical, slightly curved, hyaline and were produced on short unbranched monophialides

\section{Cultural variability of $F$. oxysporum isolates}

Among fourteen isolates of $F$. oxysporum little variation was observed. Colony of isolates THFOP-1, IEFOP-2 showed white compact mycelium with concentric ring, THFOP-2, IWFOP-2, IEFOP-1, SEFOP-1 showed white cottony mycelium growth, isolates BIFOP-1, BIFOP-2,IWFOP-1 and SEFOP-2 showed white cottony and fluffy mycelium growth, TAFOP-2, UKFOP-1 showed white cottony and fluffy mycelium growth with concentric ring while isolates TAFOP-1 showed sparsely distributed with white cottony mycelium growth and isolate UKFOP-1 showed white cottony mycelium with concentric ring. The radial growth of colony diameter on potato dextrose agar (PDA) medium ranged from 5.4 $\mathrm{cm}$ to $8.9 \mathrm{~cm}$ at 8 days after inoculation at $26 \pm 10{ }^{\circ} \mathrm{C}$ in $90 \mathrm{~mm}$ petriplates. Maximum radial growth was observed in IEFOP-1 (8.9 $\mathrm{cm})$ followed by IWFOP-2, TAFOP-2, BIFOP-2 $(8.6 \mathrm{~cm})$, SEFOP-1 $(8.5 \mathrm{~cm})$, BIFOP- 1 $(8.3 \mathrm{~cm}), \quad$ UKFOP-1 $(8.1 \mathrm{~cm}), \quad$ TAFOP-1 $(8.0 \mathrm{~cm})$, IWFOP-1 $(7.7 \mathrm{~cm})$, UKFOP-2 $(7.6$ $\mathrm{cm})$, THFOP-1, THFOP-2 $(7.5 \mathrm{~cm})$ and isolate SEFOP-2 showed least radial growth in which diameter was $5.4 \mathrm{~cm}$. Variation in the colour of mycelium was observed in all the isolates in PDA medium. Initially the colour of all isolates was white which changed gradually with different pigmentation. Isolate THFOP-1 showed dark purple, THFOP-2 showed light pink, BIFOP-1 and TAFOP-2 showed purple colour, BIFOP-2, UKFOP-2 and SEFOP-2 showed pale yellow colour, TAFOP-2 showed light yellow colour while four isolates UKFOP-1, IWFOP-2, IEFOP-1 and IEFOP-2 showed light purple colour and isolates IWFOP-1 and SEFOP-1 showed pink colour. Sporulation of all isolates showed moderate to profuse. Moderate sporulation was observed in isolates THFOP-2, BIFOP-1, BIFOP-2 
UKFOP-1, IWFOP-2. IEFOP-2, SEFOP-1 and SEFOP-2 whereas profuse sporulation was observed in isolates THFOP-1, TAFOP-1, TAFOP-2, UKFOP-2, IWFOP-1 and IEFOP-1 respectively. In a similar study Dubey et al., 2010; Mandhare et al., 2011 reported that
Fusarium wilt isolates were highly variable in their colony, growth pattern, size of colony, and pigmentation. Gupta et al., (2011) were also studied on cultural variability of Fusarium oxysporum f.sp pisi isolates (Table 1 and 3$)$.

Table.1 Cultural characteristics of different isolates of wilt pathogen (Fusarium oxysporum f.sp.pisi)

\begin{tabular}{|l|l|l|l|l|l|l|}
\hline $\begin{array}{l}\text { Sl. } \\
\text { no }\end{array}$ & Isolates & Location & Colony character & $\begin{array}{l}\text { Colony } \\
\text { diameter } \\
(\mathrm{cm}) \text { 8 DAI }\end{array}$ & Pigmentation & Sporulation \\
\hline $\mathbf{1}$ & THFOP1 & Charangpat & White compact mycelium in concentric ring & 7.5 & Dark purple & Profuse \\
\hline $\mathbf{2}$ & THFOP2 & Wangjing & White cottony mycelium & 7.5 & Light pink & Moderate \\
\hline $\mathbf{3}$ & BIFOP1 & Toubul & White cottony and fluffy mycelium & 8.3 & Purple & Moderate \\
\hline $\mathbf{4}$ & BIFOP2 & Bishempur & White cottony and fluffy mycelium & 8.6 & Pale yellow & Moderate \\
\hline $\mathbf{5}$ & TAFOP1 & Awangkhul & Sparsely distributed white cottony mycelium & 8.0 & Purple & Profuse \\
\hline $\mathbf{6}$ & TAFOP2 & Kahulong & $\begin{array}{l}\text { White cottony and fluffy mycelium in } \\
\text { concentric ring }\end{array}$ & 8.6 & Light yellow & Profuse \\
\hline $\mathbf{7}$ & UKFOP1 & $\begin{array}{l}\text { Kashung } \\
\text { khullen }\end{array}$ & $\begin{array}{l}\text { White cottony and fluffy mycelium in } \\
\text { concentric ring }\end{array}$ & 8.1 & Light purple & Moderate \\
\hline $\mathbf{8}$ & UKFOP2 & Litan & White cottony mycelium in concentric ring & 7.6 & Pale yellow & Profuse \\
\hline $\mathbf{9}$ & IWFOP1 & Iroisemba & White cottony and fluffy mycelium & 7.7 & Pink & Profuse \\
\hline $\mathbf{1 0}$ & IWFOP2 & Nambol & White cottony mycelium & 8.6 & Light purple & Moderate \\
\hline $\mathbf{1 1}$ & IEFOP1 & Thongju & White cottony mycelium & 8.9 & Light purple & Profuse \\
\hline $\mathbf{1 2}$ & IEFOP2 & Kongba & White compact mycelium in concentric ring & 8.6 & Light purple & Moderate \\
\hline $\mathbf{1 3}$ & SEFOP1 & Kangpokpi & White cottony mycelium & 8.5 & Pink & Moderate \\
\hline $\mathbf{1 4}$ & SEFOP2 & Mao Maram & White cottony and fluffy mycelium & 5.4 & Pale yellow & Moderate \\
\hline
\end{tabular}

Table.3 Chlamydospores and Biomass production of Fusarium oxysporum f.sp.pisi isolates

\begin{tabular}{|c|c|c|}
\hline Sl. No & Chlamydospore production (no.) & Biomass (dry weight/gm) \\
\hline $\mathbf{1}$ & 12 & 1.04 \\
\hline $\mathbf{2}$ & 14 & 0.96 \\
\hline $\mathbf{3}$ & 19 & 1.25 \\
\hline $\mathbf{4}$ & 20 & 0.88 \\
\hline $\mathbf{5}$ & 15 & 0.98 \\
\hline $\mathbf{6}$ & 21 & 1.31 \\
\hline $\mathbf{7}$ & 19 & 1.28 \\
\hline $\mathbf{8}$ & 18 & 1.27 \\
\hline $\mathbf{9}$ & 13 & 1.07 \\
\hline $\mathbf{1 0}$ & 12 & 0.78 \\
\hline $\mathbf{1 1}$ & 10 & 0.97 \\
\hline $\mathbf{1 2}$ & 10 & 0.81 \\
\hline $\mathbf{1 3}$ & 11 & 1.02 \\
\hline $\mathbf{1 4}$ & 13 & 0.87 \\
\hline
\end{tabular}


Table.2 Morphological characteristics of Fusarium oxysporum f.sp pisi isolates

\begin{tabular}{|c|c|c|c|c|c|c|c|c|c|}
\hline Sl. & Isolates & Location & Macro & nidia & & Micro co & & & Colour \\
\hline & & & $\operatorname{Size}(\mu \mathrm{m})$ & $\begin{array}{l}\text { Sept- } \\
\text { ation }\end{array}$ & Shape & $\operatorname{Size}(\mu \mathrm{m})$ & Septation & Shape & \\
\hline 1 & THFOP1 & Charangpat & $11.6 \times 3.1$ & $2-3$ & $\begin{array}{l}\text { Sickle shape with blunt } \\
\text { end }\end{array}$ & $3.0 \times 2.1$ & 0 & 0val & Hyaline \\
\hline 2 & THFOP2 & Wangjing & $12.7 \times 3.7$ & $3-4$ & Sickle shape & $3.2 \times 2.5$ & 0 & 0val & Hyaline \\
\hline 3 & BIFOP 1 & Toubul & $18.2 \times 5.3$ & $3-4$ & Sickle shape & $8.2 \times 5.9$ & 0 & Round & Hyaline \\
\hline 4 & BIFOP 2 & Bishempur & $24.9 \times 5.7$ & $3-4$ & Sickle shape & $8.5 \times 5.5$ & 0 & Round & Hyaline \\
\hline 5 & TAFOP1 & Awangkhul & $17.6 x 5.1$ & $2-3$ & Sickle shape & $5.6 \times 2.7$ & 0 & Round & Hyaline \\
\hline 6 & TAFOP2 & Kahulong & $24.5 \times 5.9$ & $2-3$ & Elongated sickle shape & $9.1 \times 5.6$ & 0 & Round & Hyaline \\
\hline 7 & UKFOP1 & $\begin{array}{l}\text { Kashung } \\
\text { khullen }\end{array}$ & $17.4 \times 5.3$ & 2.3 & $\begin{array}{l}\text { Sickle shape with blunt } \\
\text { end }\end{array}$ & $4.9 \times 2.3$ & 0 & Oval & Hyaline \\
\hline 8 & UKFOP2 & Litan & $13.6 \times 3.9$ & $2-3$ & Sickle shape & $3.2 \times 2.6$ & 0 & Oval & Hyaline \\
\hline 9 & IWFOP1 & Iroisemba & $15.8 \times 4.3$ & $2-3$ & Sickle shape & $3.3 \times 2.5$ & 0 & Oval & Hyaline \\
\hline 10 & IWFOP2 & Nambol & $21.9 \times 5.8$ & $2-3$ & Elongated sickle shape & $7.2 \times 5.2$ & $0-1$ & 0val & Hyaline \\
\hline 11 & IEFOP 1 & Thongju & $25.2 \times 6.2$ & $2-3$ & Elongated sickle shape & $9.2 \times 56$ & 0 & Round & Hyaline \\
\hline 12 & IEFOP2 & Kongba & $23.4 \times 5.6$ & $2-3$ & $\begin{array}{l}\text { Sickle shape with blunt } \\
\text { end }\end{array}$ & $7.9 \times 5.1$ & 0 & Round & Hyaline \\
\hline 13 & SEFOP1 & Kangpokpi & $20.4 \times 5.2$ & $2-3$ & $\begin{array}{l}\text { Sickle shape with blunt } \\
\text { end }\end{array}$ & $8.4 \times 5.3$ & $0-1$ & Oval & Hyaline \\
\hline 14 & SEFOP2 & $\begin{array}{l}\text { Mao } \\
\text { Maram }\end{array}$ & $11.7 \times 3.1$ & $2-3$ & $\begin{array}{l}\text { Sickle shape with blunt } \\
\text { end }\end{array}$ & $3.1 \times 2.3$ & $0-1$ & Oval & Hyaline \\
\hline
\end{tabular}

Table.4 Pathogenic variability of Fusarium oxysporum f.sp. pisi isolates

\begin{tabular}{|l|l|l|l|l|}
\hline Sl. no & Isolates & Location & Pathogenecity & Reaction \\
\hline 1 & THFOP1 & Charangpat & +++ & Pathogenic \\
\hline 2 & THFOP2 & Wangjing & +++ & Pathogenic \\
\hline 3 & BIFOP1 & Toubul & ++++ & Highly pathogenic \\
\hline 4 & BIFOP2 & Bishempur & +++ & Pathogenic \\
\hline 5 & TAFOP1 & Awangkhul & +++ & Pathogenic \\
\hline 6 & TAFOP2 & Kahulong & +++ & Pathogenic \\
\hline 7 & UKFOP1 & Kashung khullen & +++ & Pathogenic \\
\hline 8 & UKFOP2 & Litan & +++ & Pathogenic \\
\hline 9 & IWFOP1 & Iroisemba & +++ & Pathogenic \\
\hline 10 & IWFOP2 & Nambol & ++++ & Highly pathogenic \\
\hline 11 & IEFOP1 & Thongju & ++++ & Highly pathogenic \\
\hline 12 & IEFOP2 & Kongba & +++ & Pathogenic \\
\hline 13 & SEFOP1 & Kangpokpi & +++ & Pathogenic \\
\hline 14 & SEFOP2 & Mao Maram & +++ & Pathogenic \\
\hline
\end{tabular}

Up to $25 \%$ wilt for + (single plus), 25.1 to $50 \%$ for ++ (double plus), 50.1 to $75 \%$ for +++ (triple plus) and more than $75 \%$ for ++++ (tetra plus). 
Morphological variability of $F$. oxysporum isolates

Morphological variation like conidial shape, size, septation, colour and chlamydospores formation were studied using Potato Dextrose Agar medium. The size of macro conidia ranged from $11.6 \times 3 \mu \mathrm{m}$ to $25.2 \times 6.2 \mu \mathrm{m}$ and size of micro conidia ranged from $3.02 \times 2.1 \mu \mathrm{m}$ to 9.2 $\mathrm{x} 5.6 \mu \mathrm{m}$. The largest size of macroconidia was found in IEFOP-1 $(25.2 \times 6.2 \mu \mathrm{m})$ whereas smallest size was found in THFOP-1 (11.6 x 3 $\mu \mathrm{m})$ while the largest size of microconidia was also found in IEFOP-1 $(9.2 \times 5.6 \mu \mathrm{m})$ and smallest was also found in THFOP-1 (3.02x 2.1 $\mu \mathrm{m})$. The number of septation was also varied in all the isolates. In macroconidia three to four septa are found in isolates of THFOP-2, BIFOP1 and BIFOP-2 and two to three septa were found in all the remaining isolates whereas in microconidia most of the isolates was found with no septum but three isolates viz. IWFOP-2, SEFOP-1 and SEFOP-2 were found 0-1 septum. Isolates THFOP-2, BIFOP-1, BIFOP-2, TAFOP-1, UKFOP-2 and IWFOP-1 were found sickle shape macroconidia whereas isolates THFOP-1, UKFOP-1, IEFOP-2, SEFOP-1 and SEFOP-2 were found sickle shape with blunt end macroconidia while the three isolates TAFOP-2, IWFOP-2 and IEFOP-1 were found elongated sickle shape macroconidia. In microconidia most of the isolates are oval shape while isolates BIFOP-1, BIFOP-2, THFOP-1, THFOP-2, IEFOP-1 and IEFOP-2 are round shape. The conidial colour of all the isolates was found hyaline. The formation of chlamydospores ranged from ten to twentyone numbers of all the isolates on Potato Dextrose Agar medium. The dry weight mycelium showed variability in the weight of isolates. The highest dr mycelium weight was observed in TAFOP-2 (1.31g) followed by UKFOP$1(1.28 \mathrm{~g})$, UKFOP-2(1.27g), BIFOP-1(1.25g), IWFOP-1(1.07g),THFOP-1(1.04g) and SEFOP$1(1.02 \mathrm{~g})$ respectively whereas minimum dry mycelia weight of $0.78 \mathrm{~g}, 0.81 \mathrm{~g}, 0.87 \mathrm{~g}, 0.88 \mathrm{~g}$, $0.96 \mathrm{~g}, 0.97 \mathrm{~g}$ and $0.98 \mathrm{~g}$ was obtained from the isolates IWFOP-2, IEFOP-2, SEFOP-2, BIFOP2, THFOP-2, IEFOP-1 and TAFOP-1 respectively. Similarly, the cultural variability and morphological characteristics of Fusarium oxysporum f.sp. zingiberi isolatyes was reported by Dohroo and Sharma (1992) and Siddique and Kaushal(2000). Shalini Verma and Dohroo (2003) was also reported that morphological and cultural variability existed among isolates of Fusarium oxysporum f.sp.pisi. from pea in which all the isolates showed slow to fast growth, variable pigmentation and morphology of the hyphae, microconidia and chlamydospores. S.K. Gupta et al.,(2011) studied on morphological variation of Fusarium oxysporum f.sp.pisi like mycelia colour, conidial size and formation of chlamydospores (Table 2).

\section{Pathogenic variability of F.oxysporum isolates}

In pathogenic variability, pot culture experiment was done. On the basis of percentage of wilt symptom observed on pea cultivars are graded into different category. Most of the isolates showed 50.1 to $75 \%$ wilt which was graded at pathogenic isolates whereas three isolates viz. BIFOP-1, IWFOP-2 and IEFOP-1 showed more than $75 \%$ wilt and graded at highly pathogenic isolates. Therefore all the isolates exhibited wilt symptom and hence proved pathogenic on susceptible pea cultivars under artificial inoculation. Similarly, Miedner et al. (1996) studied on 42 Fusarium culmorum isolates collected from diseased plants from the field of Australia and nine European countries on a synthetic winter rye population in which all the isolates were found pathogenic and differed in their ability to cause diseases. Shanthalaxmi Prasad et al. (2008) reported that the reaction of 29 isolates of $F$. oxysporum f.sp. ricini on different castor cultivars and indicated the existence of five pathotypes of the pathogen with different level of virulence (Table 4).

From the present study it can be concluded that the cultural, morphological and pathogenic variability of Fusarium oxysporum f.sp.pisi isolates causing wilt of pea showed different characters in myselial growth pattern, 
pigmentation, rate of growth on Patato dextrose agar. The radial growth was ranged from $5.4 \mathrm{~cm}$ to $8.9 \mathrm{~cm}$ at 8 days after inoculation at $26 \pm 1^{0} \mathrm{C}$ on $90 \mathrm{~mm}$ petriplates. The colour of all the isolates are mostly white which changed gradually to light pink, purple colour, pale yellow colour etc. Sporulation of all isolates showed moderate to profuse. The size of macroconidia varied from $11.6 \times 3.1 \mu \mathrm{m}$ to 24.9 $\mathrm{x} 5.7 \mu \mathrm{m}$ and microconidia was $3.02 \times 2.1 \mu \mathrm{m}$ to $9.2 \times 5.6 \mu \mathrm{m}$. In pathogenic variability all the isolates showed pathogenic causing wilt of pea. Thus the present study provides information about the epidemiology of Fusarium that helps in improving management strategies for wilt of pea.

\section{References}

Anonymous (2015). Annual Report(2014-15) on Promotion of Pulses in NEH region. ICAR- Indian Institute of Pulses Research, Kanpur, Uttar Pradesh 208024 (India).39 pp.

Dohroo, N.P., Sharma, S.K. (1992).Variability in Fusarium oxysporum f.sp. zingiberi, the incident of ginger yellows. Indian Phytopathology 45, 247-248.

Dubey SC, Singh SR and Singh B. (2010).Morphological and pathogenic variability of Indian isolates of Fusarium oxysporum f. sp. Ciceris causing chickpea wilt. Archives of Phytopathology and Plant Protection 43(2): 174 - 190.

Gupta Om, Khare MN and Kotasthane SR. (1986).Variability among six isolates of Fusarium oxysporum f. sp. Ciceri causing wilt of chickpea. Indian Phytopathology 39: 279-281.

Gupta SK, Ranas and Jarial K. (2011). Variation in morphological, cultural, pathological and molecular features of Fusarium oxysporum f. sp. pisi isolates causing wilt of pea (Pisum sativum L.). $J$ Mycol Plant Pathol 41(2):275-278.

Linford,M.F.(1928).A Fusarium wilt of pea in Wisconsin.Wisconsin Agricultural Experiments Station, Bulletin. 85: 28-30.

Mandhare VK, Deshmukha VK, Patil JV, Kale AA, and Chavand UD.(2011). Morphological, pathogenic and molecular characterization of Fusarium oxysporum f. sp. Ciceri isolates from Maharashtra, India. Indonesian Journal of Agricultural Science 12 (2): 47-56.

Meidner T, Gang G and Geiger H H (1996). Quantitative genetic basis of aggressiveness of 42 isolates of Fusarium culmorum for winter rye head blight. Plant Disease 80:500-504.

Sardana,S., Mahajan, R.K., Gautam, N.K. and Ram, B (2007). Genetic variability in pea (Pisum sativum L.) germplasm for utilization. SABRAO Journal of Breeding and Genetics, 39(1): 31-41.

Santhalaxmi Prasad M, Sujatha M and Raoof M A (2008). Morphological, pathogenic and genetic variability in castor wilt isolates. Indian Phytopathology 61: 18-27.

ShaliniVerma and Dohroo N P. (2003). Morphological, cultural and pathogenic variability in Fusarium oxysporum isolates from pea. Plant Disease Research 18(1): 5-8.

Siddiqui,M.Z., Kaushal, V.K., 2000. Studies on certain pathological aspects of rhizome rot and wilt of ginger (Zingiber officinale Rosc) in Bundelkhand Region. Flora and Fauna Jhansi 6, 97-100.

Smartt,J (1990). Grain Legumes: Evolution and Genetic resources. Cambridge University Press, Cambridge, UK.

\section{How to cite this article:}

Kripalini, N., Mohan Kumar Biswas and Ph. Sobita Devi. 2018. Studies on Morphological, Cultural and Pathogenic Variability in Isolates of Fusarium oxysporum f.sp. pisi Causing Wilt of Pea from Different Districts of Manipur, India. Int.J.Curr.Microbiol.App.Sci. 7(11): 2500-2506. doi: https://doi.org/10.20546/ijcmas.2018.711.284 